\title{
Trends in portfolio management
}

Received: 30th May, 2001

\section{Michael O'Brien}

is Head of BGl's Multinational Client Relationship Team in Europe together with being responsible for Product Strategy for BGI's European Institutional Business. Prior to joining Barclays Global Investors in July 2000, he spent over ten years at Towers Perrin where he was responsible for the development of the firm's asset strategy consulting activities in the UK and Europe. He has extensive experience in the development and implementation of investment strategies for UK and European corporate pension plans. He is a Fellow of the Institute of Actuaries having graduated from Limerick University with a degree in Applied Mathematics. He is also a CFA charterholder.

Keywords: investment strategy development; benchmarks; market-neutral; hedge funds; risk budgeting

\begin{abstract}
Time waits for no man. With the growing impact pension plans now exert on the finances of the plan sponsor, there is an increasing demand for plan assets to be managed more efficiently both at a strategic level and at the individual portfolio level. At the same time, the pace of economic developments combined with increasingly sophisticated financial techniques and original research is challenging the 'old ways' of doing things. Clearly, this dynamic environment on the supply side, combined with a demand for new ideas from plan sponsors, will reinforce current trends and further reinforce the pace of change in the manner in which pension plan assets are managed.
\end{abstract}

Michael O'Brien Barclays Global Investors 4th Floor, 1 Royal Mint Court, London EC3N 4HH.

Tel: +44 (0)20 7668 8644; e-mail: Michael.O'Brien@ barclaysglobal.com
It is now widely accepted that the size of funded corporate pension plans is growing rapidly worldwide. This is resulting in increasing instances where the total funded assets now exceed the share capital of the sponsoring employer - for example BA's UK pension plan assets alone exceed $\mathcal{E} 10 \mathrm{bn}$ representing over 180 per cent of the market value of the company. The issue is becoming more acute, not only as a result of further consolidation through mergers and acquisitions within many industries, but also due to the decision by companies in many countries to commence funding their pension obligations.

Coupled with this is an increasing focus among shareholders on management's ability to derive increasing efficiencies from the business. To satisfy these expectations, companies are now investigating various areas where these cost efficiencies can be sought - these include pooling insurance and risk management, administration outsourcing, and improving the financial management of the company's pension plans. Here this paper will focus on increasing the efficiency of the management of the pension plan's assets and on the current trends in this area. In particular, the paper will address the issue of benchmark index selection and the role of removing/weakening the 'long only' constraint placed on traditional managers in the context of implementing active equity management.

The management of a plan's assets is an area offering substantial scope for increased efficiencies. Simply increasing the long-term investment return by 1 per 


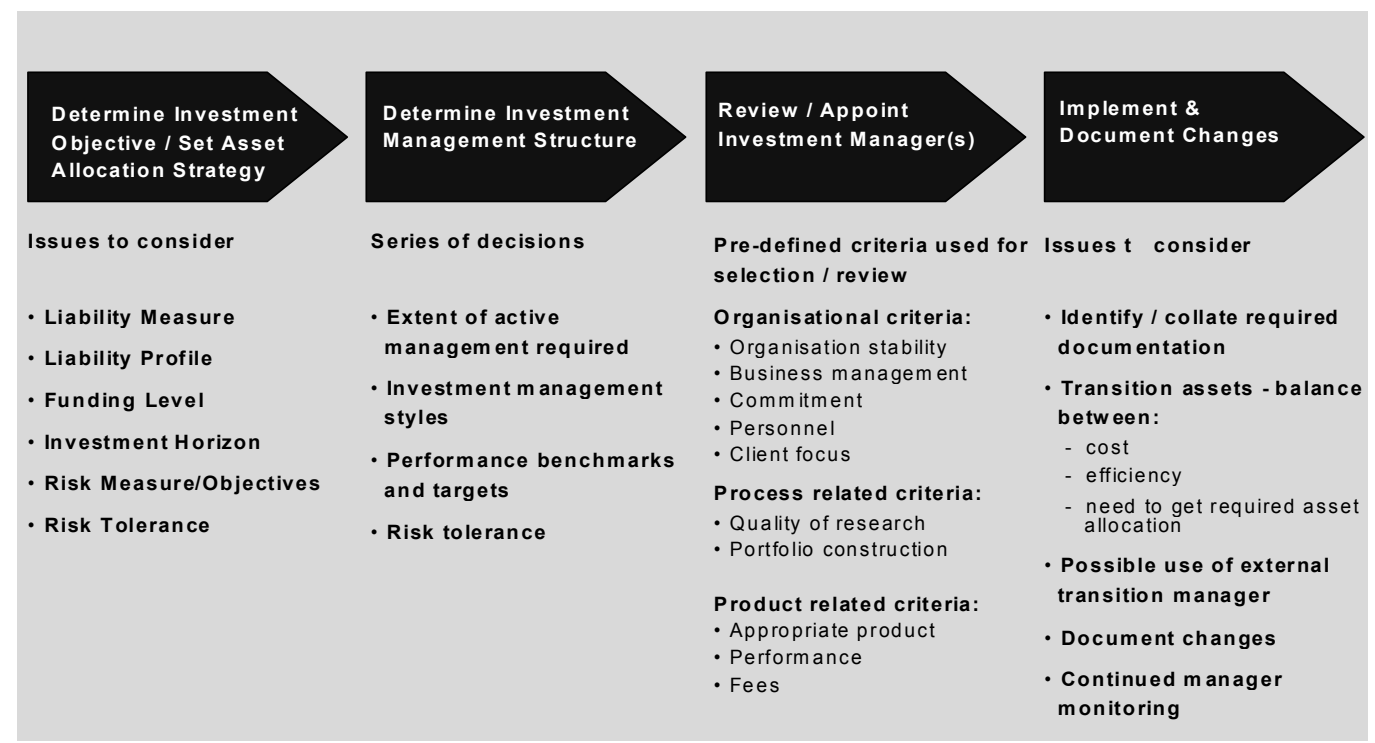

Figure 1: Developing and implementing an investment strategy

cent pa, for example, can reduce the cost of providing employees' pensions by up to 20 per cent - the attraction here is the ease with which many organisations can improve on how they currently develop and implement investment policies. This area has now started to attract increased attention from both plan sponsors and plan fiduciaries, a trend that no doubt will be reinforced by the release of FRS17 and the Myners Report.

The shape and form of any portfolio, whether bonds or equities, will depend on decisions taken at the strategic asset allocation level. Due to the increased focus on the impact of pension plans on the financial strength of the sponsoring company, we are now witnessing an increase in the time and effort being directed into the alignment of a pension plan's investment strategy with the risks facing the fiduciaries and the sponsor. Reinforcing this increased attention is a robust process operated by a number of plans when developing an investment policy - the process commences with the identification of the risks to be managed, the definition of failure to manage these risks, and the eligible asset classes available to manage these risks. Figure 1 clearly shows the modular nature of a standard investment policy process covering the design, development, implementation and monitoring of a plan's investment policy.

Once the objectives to be achieved and the appropriate definitions of risk have been agreed (often not a simple task due to the potentially conflicting nature of the sponsor's requirements and the fiduciaries' requirements), the next step is to investigate the impact of a variety of asset mixes on the achievement of these objectives within the specified risk constraints. This is normally undertaken via the use of an asset-liability study. Out of this will fall an agreed asset mix comprising strategic allocations to a variety of asset classes this sets the scene for the specification of the portfolio mandates ultimately presented to the investment managers.

Having decided on the preferred exposures to the various systematic market risks, ie, UK equities, global 
equities, property etc, the next step is to decide the types of investment manager to be appointed to implement the exposure to each. At a basic level this often comes down to the decision between index and active management for each asset class. The first step here is to decide what performance benchmark to use for each asset class - more on this later. Once the performance benchmark has been agreed the next step is to decide the extent to which active management will be employed and, if so, what level of risk should the active manager be mandated to work with (ie, target tracking error) and the desired target level of out-performance. This concept of 'risk budget' (ie, the process whereby the plan sponsor/fiduciaries decide how much risk they wish to introduce through active investment management and where this risk should be applied - UK equity small cap, European equities etc) has now become well ingrained in modern portfolio management. In their recent report, 'Success in Investment Management Building and Managing the Complete Firm', Merrill Lynch/Barra Strategic Consulting confirm this trend. In the report, they state that, "buyers will scrutinise the manufacturers' "risk budget"'. In a domestic equity product, the manager can add value through 'risk factors (style), industry allocation or stock selection. Scrutiny of these alpha contributions will become the norm'. Consequently, mangers will be expected to clearly articulate their sources of alpha (out-performance). The report goes on to state that, 'to maintain a competitive advantage in investments, firms must be aware of their potential opportunities for alpha generation, focus on and highlight their alpha generation advantage capability, and neutralise areas where they have no advantage (risk budgeting)'.

While the selection of an appropriate benchmark index at one time may have been a simple task, times change. Due to the variety of indices and index providers now in the market, combined with issues such as free-float, stock concentration and sector weightings, this task is no longer as simple as it seems. Taking for example global equities, there are at least four possible candidate indices here alone, namely: FT-World Index Series, MSCI World Index, S\&P Global 1200 and Salomon Smith Barney World Equity Index. The benchmark specification combined with the target tracking error and required performance will represent the largest influences on the manner in which the investment manger will build and manage the portfolio - hence fiduciaries/plan sponsors are spending more time on this subject.

So what defines a good benchmark? For both equity and bond indices, there are certain key criteria to be met for an index to be a suitable investment benchmark. These criteria can be applied regardless of whether the actual strategy employed is active or indexed. The principal criteria are defined in Table 1.

Expanding on the earlier example of the various indices available for mainstream asset classes, looking again at global equities, analysis undertaken by BGI illustrates the considerable differences that exist between the various benchmark indices. ${ }^{1}$ Clearly selecting a benchmark index is not a simple task.

However, even within mainstream equity benchmarks/indices that satisfy the above criteria, the issues of stock and sector concentration and capitalisation profiles are complicating matters for all involved. The trend is firmly towards plan sponsors/fiduciaries/consultants spending more time and effort understanding the implications of using a particular index and the associated implicit sector, style and capitalisation biases. For example, the index you 
Table 1: Criteria required

\begin{tabular}{ll}
\hline Criteria & Definition \\
\hline Relevant & $\begin{array}{l}\text { The benchmark should seek to meet the objectives of the underlying investment strategy } \\
\text { Representative }\end{array}$ \\
$\begin{array}{l}\text { The benchmark should be a fair representation of the universal characteristics of the } \\
\text { market sectors included }\end{array}$ \\
$\begin{array}{l}\text { Transparent } \\
\text { Replicable }\end{array}$ & $\begin{array}{l}\text { There should be clear rules on methodology, index changes, eligibility criteria } \\
\text { Constituent level data, index performance data and other information relating to the index } \\
\text { should be widely disseminated in the market to allow the implementation of an index } \\
\text { strategy, performance measurement and reporting etc. }\end{array}$ \\
Investible & $\begin{array}{l}\text { The benchmark should include issues that can be invested in by a wide variety of } \\
\text { investors and meet basic liquidity criteria }\end{array}$ \\
Flexible & $\begin{array}{l}\text { The dimensions along which the index can be split should be as broad as possible, eg } \\
\text { maturity, issuer type, credit rating and possibly customisable }\end{array}$ \\
Consistent & $\begin{array}{l}\text { The index rules should enable the constituents comprising the index to remain stable } \\
\text { from one month to the next (ie low turnover) }\end{array}$ \\
\hline
\end{tabular}

Note: In the context of an equity index, there are two additional considerations, namely the existence of derivatives and good crossing opportunities.

choose will influence the capitalisation, stock and sector profiles of your portfolio, and hence ultimately your portfolio's performance. This became evident during 2000 when the TMT (Technology, Media, Telecommunications) laden MSCI US equity index significantly under-performed the more traditional S\&P 500 index with the S\&P500 falling by 10.1 per cent (in US\$) while the MSCI fell by 12.9 per cent (again in US\$).

To complicate matters further associated with index selection, the issues of stock, sector concentration etc are not restricted to the US. Looking at the European equity market, the issue of stock concentration is raising questions about how representative the principal indices are of the underlying markets. Nowhere is this more pronounced than in the UK where pension plans have a history of not only operating a high allocation to equities (around 80 per cent as at 31st December 2000), but also maintaining a strong home bias (of the order of 70 per cent of total equities). Looking at Table 2 below we see that, while stock concentration has always been an issue for smaller markets like
Sweden and Finland, the issue has now become much more severe for the UK. Based on this data and assuming that the average UK plan allocated approximately 55 per cent to UK equities, the net result is the average plan allocating almost as much to Vodafone (9 per cent of the FTSE All-Share) as to the US equity market (which incidentally accounts for over 50 per cent of the world equity market capitalisation).

How are UK plans, for example, reacting to this challenge to efficient portfolio configuration? Well, in a number of ways.

In terms of coping with stock concentration, plans are adopting a number of approaches:

- reducing the allocation to the UK equity market;

- capping the allocation to individual stocks at, say 10 per cent;

- redefining asset classes to incorporate UK equities into a broader category, ie European or Global Equities;

- splitting the equity universe into multinational and local companies.

On a more fundamental issue, namely the question relating to the overall 
Table 2: Stock concentration in global markets per cent (MSCl)

\begin{tabular}{llrrr}
\hline Country & $\begin{array}{l}\text { Largest } \\
\text { stock }\end{array}$ & Top 3 & Top 5 & Top 10 \\
\hline Belgium & 20.52 & 47.42 & 64.97 & 86.15 \\
Finland & 79.14 & 88.15 & 94.69 & 100.00 \\
France & 10.94 & 24.83 & 36.50 & 57.65 \\
Germany & 10.99 & 28.81 & 42.75 & 64.95 \\
Netherlands & 25.86 & 49.23 & 64.61 & 85.12 \\
Sweden & 30.06 & 45.84 & 56.70 & 70.88 \\
UK & 9.27 & 25.98 & 36.39 & 50.38 \\
Europe (ex-UK) & 3.03 & 8.64 & 12.93 & 21.69 \\
Europe (inc-UK) & 3.04 & 8.49 & 12.63 & 20.60 \\
Japan & 5.46 & 11.88 & 16.01 & 24.98 \\
US & 4.80 & 11.23 & 16.92 & 28.14 \\
\hline
\end{tabular}

Source: $\mathrm{MSCl}, \mathrm{BGI}$

appropriateness of the various benchmark indices, a number of large institutional investors are beginning to question the relevance of using benchmark indices in terms of seeking active manager performance. In particular, they are beginning to question the efficiency of mandating active investment managers to build portfolios with close reference to a particular index. This change of attitude is also partly as a result of the increased tendency of some active managers to manage their own business risk, often at the expense of their client's return expectations and closet index significant proportions of their active portfolios.

The result is a trend (predominately in the USA currently) towards the use of hedge fund/absolute-return strategies, in particular market-neutral strategies. These are designed to secure absolute/positive performance which can then be transferred onto the desired strategic asset class (for example, long bonds for mature liabilities) through the use of index funds or derivatives - colloquially referred to a 'portable alpha'.

While absolute return/hedge fund strategies were first applied in the USA in the 1940s, it is only relatively recently that the market preconditions and technical knowledge for running these funds has become more widely available. The result has been an explosion of interest in the advantages of incorporating hedge fund strategies into portfolios. A recent survey undertaken by Golin/Harris Ludgate into institutional investor perception of hedge funds confirms the degree of interest in these strategies.

In terms of improving portfolio efficiency, hedge funds (and, in particular, market-neutral funds) represent a means to significantly increase overall efficiency, both at:

- the total portfolio level, due to the low and stable correlation and volatility characteristics associated with these strategies;

- the individual equity/bond portfolio level due to the more efficient application of the manager's investment skill.

With respect to the latter point, market neutral/absolute return strategies provide a more efficient framework for investment skill to be captured in portfolios and realised by clients. This is because market neutral positions reflect investment views, not benchmark weights, while traditional long-only portfolios are constrained by the necessity to provide benchmark related returns and the fear of failing to do so! Traditional long-only managers already take long and 
short positions in, for example, UK equities relative to their benchmark, the FTSE-All Share Index. However, they are constrained by the fact that the lowest allocation they can make to a stock they do not like is 0 per cent they are constrained by the fact that they cannot sell short (and fully utilise the value of their research and views on poor stocks). A short position in a stock is achieved by borrowing a stock and then subsequently selling it with an expectation that it will fall in value. When the expected return has been achieved (and the stock has fallen in price), the manager buys the stock in the market and returns it to the stock lender. Therefore, by utilising the scope to sell short, a market neutral framework creates a more effective and efficient environment to capture investment skill (and provide a return for research in this area of the market).

So how effective is the removal of the 'long-only' constraint and the introduction of shorting in increasing the return per unit of risk provided by an investment manager with a given level of skill. Research undertaken by BGI into this area indicates that, for a given level of manager skill, long-short strategies offer the potential for a significant improvement in risk-adjusted return expectations vis-à-vis traditional long-only strategies. This is particularly true when the universe of investible assets is large, asset volatility is low, and the actual strategy to be implemented has high levels of active risk. While previous research in this area has focused particularly on the benefits of long-short strategies benefiting from the research inefficiencies on the short side and the cost of shorting, in our view the real benefit of long-short strategies comes primarily from the loosening of the long-only constraint.

The research indicated that the nature of the benchmark is crucial in determining the increased efficiency in terms of risk-adjusted return expectations. To simplify the problem we start with an equal-weighted benchmark and some forecasts of active returns (alphas) for the individual stocks contained in that benchmark.

We can express our alphas as: ${ }^{2}$

Alpha = Investment Skill $\times$ Stock Volatility $\times$ Stock Score

where

Investment $=$ The correlation of

Skill forecast returns with their subsequent realisations

Stock $\quad=$ The annualised standard

Volatility deviation of the stock's residual return (the part of the stock's return that is independent of the benchmark)

Stock $=$ The investment managers

Score ranking of the stock, normalised with a mean of zero and standard deviation of one.

Using this, we can further derive the effect of the long-only investment constraint on our ability to use our alphas to maximise the overall portfolio return. This long-only constraint becomes binding when the active stock position plus the benchmark holding is negative: ${ }^{2}$

Stock

Score $\quad<\frac{- \text { Stock Volatility }}{\sqrt{ }(N) \times \text { Active Risk }}$

where

$\mathrm{N} \quad=$ The number of stock in the benchmark 


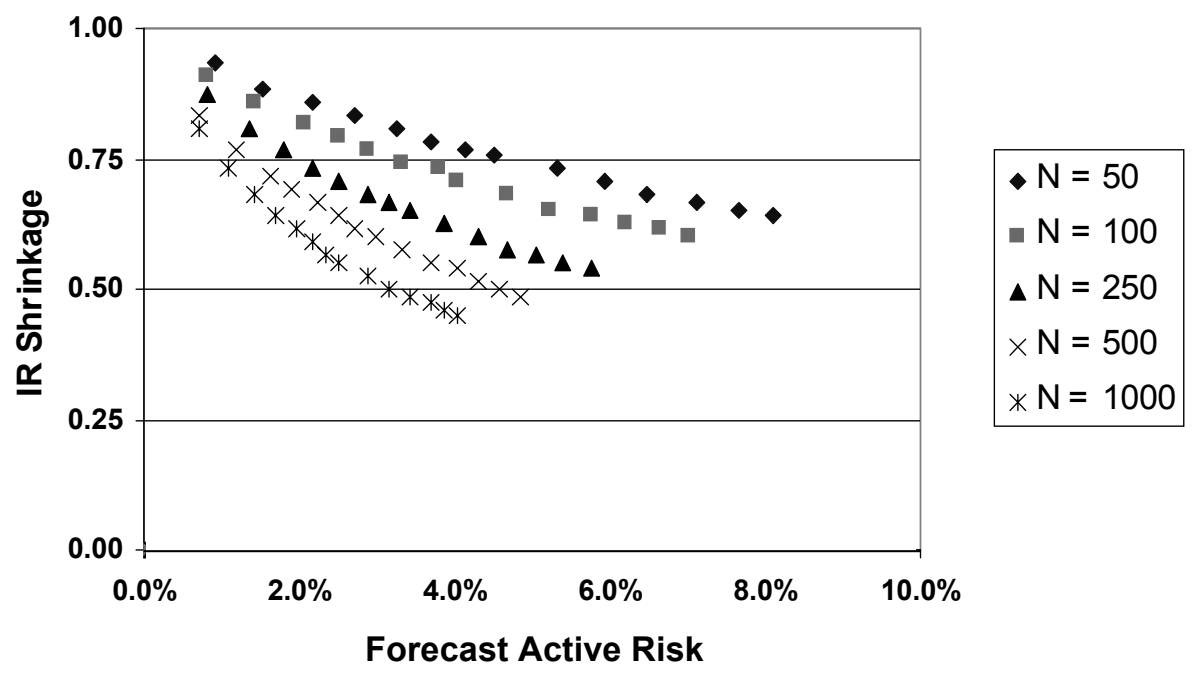

Figure 2: The impact of the long-only constraint on portfolio efficiency

Active

Risk $=$ The annualised standard deviation of the portfolio's active returns.

Thus the more stocks in the benchmark, the more the manager will benefit from moving from the long-only framework to the long-short world. For example, a manager running a portfolio against the FTSE All-Share, which contains nearly 800 stocks, will experience nearly three times (squrt(800/100)) the portfolio efficiency gain of a manager whose benchmark is the FTSE100.

Moreover, the higher the degree of active risk required relative to that benchmark, the more the manager will benefit from moving from the long-only framework to the long-short world. Conversely, at particularly low levels of risk, the extra costs involved in shorting stocks may rule out much of the potential added value. Similarly, the more volatile the residual stock returns in the benchmark, the less binding the long-only constraint is.

This simple model $^{2}$ can be adapted to allow for a capitalisation-weighted benchmark, and use this to look at the reduction in portfolio efficiency brought about by the no-shorting (or long-only) constraint while varying the number of stocks in the benchmark and the level of active risk required.

In this case, the information ratio is used as the measure of portfolio efficiency, where

$$
\begin{aligned}
& \text { Information } \\
& \text { Ratio }
\end{aligned}
$$

Next we examine the shrinkage in the information ratio as the measure of the reduction in portfolio efficiency due to imposing a long-only constraint on the manager. From Figure 2 we see that the shrinkage factor for a long-only strategy vis-à-vis a long-short strategy is approximately 30 per cent where the long-only strategy is following 500 stocks with only 2 per cent active risk. A case for enhanced indexation? However, once the universe is widened to say $800-1,000$ stocks and increase the active risk (tracking error) target to above 4 per cent, we see the impact of the long-only constraint — the 



Figure 3: A traditional portfolio can be split into passive and active positions

efficiency of the portfolio is effectively cut in half.

On the basis of this research, together with our experience of developments across the world, we expect fiduciaries to begin to consider implementing, for example, aggressive active global equity mandates by separating the market exposure (or beta) from the manager skill (alpha) and opting to purchase each separately. This can be achieved by simply using index funds or futures to capture the market exposure and capturing manager skill through a market-neutral fund operating with the appropriate return-risk profile. For example, consider an active global equity mandate where the desired tracking error is 5 per cent with a return expectation of 2.5 per cent (ie an information ratio of 0.5 ). The traditional approach is simply to appoint an active manager who will operate at this level of tracking error and has the appropriate level of skill to deliver the return expectations. The principal drawback is that, while this manager will actively manage the portfolio, at least 60 per cent -70 per cent of the portfolio will be indexed (the 'index-lag' effect), and the manager will be constrained from applying his/her skill to benefit from research into poor stocks. Alternatively, as can be seen from Figure 3, for a European equity portfolio one could simply allocate a proportion of the assets to an index fund (or purchase an appropriate futures contract) to secure the market exposure. One can then allocate the remainder of the assets to a market-neutral fund which will deliver the alpha (with a higher degree of confidence due to the removal of the long-only constraint).

In summary, time waits for no man. With the growing impact pension plans now exert on the finances of the plan sponsor, there is an increasing demand for plan assets to be managed more efficiently both at a strategic level and at the individual portfolio level. At the same time, the pace of economic developments combined with increasingly sophisticated financial techniques and original research is challenging the 'old ways' of doing things. Clearly, this dynamic environment on the supply side, combined with a demand for new ideas from plan sponsors will reinforce the trends we are currently witnessing and further reinforce the pace of change in the manner in which pension plan assets are managed. 


\section{Notes}

1 BGI Investment Insights Volume 3 Number 4 December 2000, International Equity Benchmarks - Assessing the Alternatives, Contemplating the Tradeoffs.

2 A full derivation of the formulae quoted here is outside the scope of this article. For a complete treatment see the 2nd edition Active Portfolio

Management by Richard Grinold and Ronald Kahn (published by McGraw Hill). Richard Grinold and Rohn Kahn are Managing Directors in Barclays

Global Investors Active Strategies Research Group. 